\title{
Rhizosphere protists are key determinants of plant health
}

\section{Stefan Geisen}

Wu Xiong

Yuqi Song

Keming Yang

Yian Gu

Zhong Wei

George A. Kowalchuk

Yangchun Xu

Alexandre Jousset

Qirong Shen

\section{Video Byte}

Keywords: Rhizosphere, Ralstonia solanacearum, Protists, Predator-prey interactions, Secondary metabolite genes, Plant health, tomato, pesticide, agriculture, soil, soil microbes, Microbiome

Posted Date: October 27th, 2020

DOI: https://doi.org/10.21203/rs.3.rs-99167/v1

License: (c) (i) This work is licensed under a Creative Commons Attribution 4.0 International License. Read Full License 


\section{Abstract}

Plant health is essential for food production, but plants are often affected by pathogens that can threaten plant performance including crop yield. Unfortunately, we can often only predict plant health when pathogens have infected plants and can no longer be controlled - and by then it is too late. To counteract pathogens, farmers often apply extensive amounts of pesticides throughout plant growth. But excessive pesticide use is costly and affects the biodiversity of the surrounding species. A recent study sought to find a way to predict plant health before planting. Researchers investigated different classes of soil microbes throughout the growth of tomato plants. They found that bacterial predators called protists were the best predictors of pathogen dynamics in growing plants. Although further studies will determine the mechanism of the association between protists and overall resistance to pathogens, the results of the study suggest that targeted microbiome engineering could help farmers determine the likelihood of successful planting based on the microbes present in the soil, enabling them to have more success without the use of costly and unsustainable levels of pesticides. 